\title{
Identification of Peracetylated Quercetin as a Selective 12-Lipoxygenase Pathway Inhibitor in Human Platelets ${ }^{\mathrm{S}}$
}

\author{
Marco S. Doucet, Jean-Luc Jougleux, Samuel J. Poirier, Marc Cormier, Jacob L. Léger, \\ Marc E. Surette, Nicolas Pichaud, Mohamed Touaibia, and Luc H. Boudreau \\ Department of Chemistry and Biochemistry, Université de Moncton, Moncton, Canada (M.S.D., J.-L.J., S.J.P., M.C., J.L.L., M.E. \\ S., N.P., M.T., L.H.B.) and Centre de Recherche, Département de Médecine, Institut Universitaire de Cardiologie et de \\ Pneumologie de Québec, Québec, Canada (S.J.P.)
}

Received July 9, 2018; accepted October 31, 2018

\section{ABSTRACT}

The inflammatory response is necessary for the host's defense against pathogens; however, uncontrolled or unregulated production of eicosanoids has been associated with several types of chronic inflammatory diseases. Thus, it is not surprising that enzymes implicated in the production of eicosanoids have been strategically targeted for potential therapeutic approaches. The 12(S)-hydroxyeicosatetraenoic acid [12(S)-HETE] lipid mediator is among inflammatory molecules that are abundantly produced in various diseases and is primarily biosynthesized via the 12(S)lipoxygenase pathway. The effects of the abundance of 12(S)-HETE and its contribution to several chronic inflammatory diseases have been well studied over the last few years. While most developed compounds primarily target the 5-lipoxygenase (5-LO) or the cyclooxygenase (COX) pathways, very few compounds selectively inhibiting the 12-lipoxygenase (12-LO) pathway are known. In this study, we examined whether the distribution of hydroxyl groups among flavones could influence their potency as 12-LO inhibitors. Using human platelets, the human embryonic kidney 293 (HEK293) cell line expressing 5-LO, and human polymorphonuclear leukocytes (PMNLs) we investigated the effects of these compounds on several inflammatory pathways, namely, 12-LO, 5-LO, and COX. Using high-resolution respirometry and flow cytometry, we also evaluated some normal cell functions that could be modulated by our compounds. We identified a peracetylated quercetin (compound 6) that exerts potent inhibitory activity toward the platelet 12 -LO pathway $\left(\mathrm{IC}_{50}=\right.$ $1.53 \mu \mathrm{M})$ while having a lesser affinity toward the COX pathway. This study characterizes the peracetylated quercetin (compound 6) as a more selective platelet-type 12-LO inhibitor than baicalein, with no measurable nontargeted effects on the platelet's activation or overall cell's oxygen consumption.

\section{Introduction}

Inflammatory lipid mediators are essential in coordinating the various steps of the inflammatory response. While the response is critical for the host's defense against pathogens, uncontrolled or unregulated production of these lipid mediators have been associated with chronic inflammatory diseases

The authors declare that there are no conflicts of interest regarding the publication of this paper

Blood was obtained from healthy consenting volunteers. This research project was approved by the Comité d'Éthique de la Recherche avec les Êtres Humains at the Université de Moncton.

L.H.B. was supported by the Canadian Institutes of Health Research, the New Brunswick Innovation Foundation (NBIF), and the Université de Moncton. M.T. was supported by the Natural Sciences and Engineering Research Council of Canada (NSERC), the Canadian Foundation for Innovation, the NBIF, and the Université de Moncton. J.-L.J. was a recipient of a New Brunswick Health Research Foundation and Maritime SPOR Support Unit postdoctoral fellowship. The work of N.P. is supported by grants from the NSERC, NBIF, and Université de Moncton. M.E.S. was supported by the NBIF.

https://doi.org/10.1124/mol.118.113480.

S This article has supplemental material available at molpharm. aspetjournals.org. such as arthritis (Chen et al., 2006, 2008; Giera et al., 2012), cardiovascular diseases (Cyrus et al., 1999; Mehrabian et al., 2002), asthma (Leff et al., 1998), and several types of cancer (Honn et al., 1994; Ding et al., 2001; Sarveswaran et al., 2015). The 12(S)-hydroxyeicosatetraenoic acid [12(S)-HETE] lipid mediator is among these inflammatory molecules abundantly found in various diseases (reviewed in Porro et al., 2014) and is primarily biosynthesized via the 12-lipoxygenase (12-LO) pathway. The 12-LO is highly expressed in blood platelets (Funk et al., 1990) and catalyzes the bioconversion of arachidonic acid into 12-hydroperoxy-5,8,10,14-eicosatetraenoic acid, which is then immediately reduced to $12(S)$-HETE (Hamberg and Samuelsson, 1974). While other inflammatory lipid mediators such as leukotrienes and prostaglandins have been extensively studied in numerous inflammatory diseases, the role of 12(S)-HETE remains somewhat elusive (reviewed in Porro et al., 2014). However, 12(S)-HETE has been linked to several types of inflammatory diseases. For instance, $12(S)$-HETE promotes the horizontal transfer of bioactive content between cells in the synovial fluid of rheumatoid arthritis patients (Duchez et al., 2015), increases the formation

ABBREVIATIONS: 5-LO, 5-lipoxygenase; 12-HHT, 12-hydroxyheptadecatrienoic acid; 12-LO, 12-lipoxygenase; 12(S)-HETE, 12(S)-hydroxyeicosatetraenoic acid; 15-LO, 15-lipoxygenase; CAPE, caffeic acid phenethyl ester; COX, cyclooxygenase; DMSO, dimethylsulfoxide; DPPH, 2,2diphenyl-1-picrylhydrazyl; ETS, electron transport system; HEK293, human embryonic kidney 293; PDB, Protein Data Bank; PGB ${ }_{2}$, prostaglandin $\mathrm{B}_{2}$; PMNL, polymorphonuclear leukocyte; RP-HPLC, reversed-phase high-performance liquid chromatography. 
of fatty lesions in a murine model of atherosclerosis (Cyrus et al., 1999), stimulates cancer cell proliferation (Ding et al., 2001), increases prostate tumor cell invasion (Liu et al., 1997), and enhances melanoma progression (Kang et al., 2013) in several types of cancer.

Since chronic inflammation is the foundation and a key manifestation for various inflammatory diseases, it is not surprising that enzymes implicated in the production of eicosanoids have been strategically targeted for potential therapeutic approaches (Liu et al., 1996; Leff et al., 1998; Nelson et al., 2007; Tardif et al., 2010). While most developed compounds primarily target the 5-lipoxygenase (5-LO) or the cyclooxygenase (COX)-1 or COX-2 pathways, very few compounds have been designed to selectively inhibit the $12-\mathrm{LO}$ pathway. Given the abundance and physiologic importance of $12(S)$-HETE in several inflammatory diseases, it is surprising that this enzyme has not been the focus of more pharmacological targeting.

Among the compounds that have generated interest in the field of eicosanoid inhibitors are naturally occurring polyphenols including the flavonoids, a class of bioactive plant compounds that exhibit several beneficial properties including antiinflammatory and antioxidant capacities, and even decrease some cardiovascular risks (Werz, 2007; Boudreau et al., 2012, 2017; Macready et al., 2014). These compounds are integrated naturally into our daily diet by consumption of various plants (i.e., berries, citrus fruits, and celery) (Pérez-Cano and Castell, 2016). Recent studies have shown that flavonoids and some newly designed structural analogs can decrease the production of inflammatory lipid mediators by inhibiting several inflammatory enzymes including 5-LO (Werz, 2007; Boudreau et al., 2012), 12-LO (Sekiya and Okuda, 1982; Boudreau et al., 2017), as well as COX-1 and COX-2 (Ribeiro et al., 2015). Among the flavonoids, flavones are a subgroup of polyphenolic compounds widely distributed in fruits and vegetables. Previous studies have reported activities of flavones as antiinflammatory, anticancer, and antioxidant agents (Ferrándiz and Alcaraz, 1991; Cárdenas et al., 2006). Among the flavones, baicalein is the chosen compound for most 12-LO inhibition studies (Deschamps et al., 2006; Xu et al., 2013), but has never been used in clinic as a therapeutic approach for inflammatory diseases, in part due to its nonspecificity toward other lipoxygenases (Deschamps et al., 2006; Lapchak et al., 2007). Hence, the overall objective of this study is to search for better naturally occurring products that may exhibit more potent beneficial properties and more specific effects on the platelet-derived 12-LO pathway than baicalein. Consequently, these novel 12-LO pathway inhibitors may be used as reference compounds, instead of baicalein, in future studies investigating the roles of 12-LO-derived products in the inflammatory response involving platelets.

In this study, we examined whether the distribution of hydroxyl groups among flavones could influence their potency as 12-LO pathway inhibitors. The effects of the selected flavones are compared with caffeic acid phenethyl ester (CAPE) (compound 5), a natural polyphenolic compound that has anti-inflammatory effects by inhibiting 5-LO (Boudreau et al., 2012; Tolba et al., 2013). In addition, we investigated the specificity of these compounds for the platelet-derived 12-LO pathway by evaluating the compound's ability to inhibit other inflammatory enzymes such as 5-LO and COX-1.

\section{Materials and Methods}

Study Compounds. Figure 1 shows the various flavonoids that are the object of this study. The structure of these naturally occurring compounds varies based on the distribution of hydroxyl groups. CAPE (compound 5) was included as a polyphenol reference standard with known inhibitory activity against lipoxygenases (Boudreau et al., 2012; Tolba et al., 2013). Additionally, we performed acetylation and methylation of the phenolic hydroxyls of quercetin (compound 3) (Fig. 2), generating compounds (compounds 6-8), to investigate the effect of removal of hydroxyl groups on the inhibitory activity. Such modifications can improve the bioavailability and stability of polyphenolic compounds (De Clercq and Field, 2006).

Acetylated and Methylated Quercetin Analog Synthesis. Pentaacetylquercetin [2-(3,4-diacetoxyphenyl)-4-oxo-4H-chromene3,5,7-triyl triacetate] (compound 6) was synthesized and purified, according to a published procedure (Picq et al., 1982), from quercetin and acetic anhydride. Even with an excess of 10 equivalents of iodomethane, only retusin [(2-(3,4-dimethoxyphenyl)-5-hydroxy-3,7-dimethoxy4Hchromen-4-one] (compound 7) was obtained after purification by flash chromatography (Cormier et al., 2017). Penta-O-methylquercetin (compound 8) was obtained with a large excess of iodomethane after purification by flash chromatography (Moalin et al., 2011; Cormier et al., 2017)

Platelet Isolation. Platelets were isolated as previously described (Boilard et al., 2011). Briefly, whole blood was collected from healthy consenting volunteers in tubes containing citrate dextrose as an anticoagulant and then centrifuged at $500 \mathrm{~g}$ for 10 minutes. Platelet-rich plasma was isolated and centrifuged at $400 \mathrm{~g}$ for 2 minutes at room temperature. The supernatant was then centrifuged at $1300 \mathrm{~g}$ for 10 minutes to pellet platelets. Cells were resuspended in Tyrode Buffer pH 7.4 (134 mM NaCl, $2.9 \mathrm{mM} \mathrm{KCl,} 0.34 \mathrm{mM} \mathrm{Na}_{2} \mathrm{HPO}_{4}$, $12 \mathrm{mM} \mathrm{NaHCO}_{3}, 20 \mathrm{mM}$ HEPES, $1 \mathrm{mM} \mathrm{MgCl}_{2}, 5 \mathrm{mM}$ glucose, and $0.5 \mathrm{mg} / \mathrm{ml}$ bovine serum albumin) at $10^{8}$ cell $/ \mathrm{ml}$ in the presence of $5 \mathrm{mM}$ of $\mathrm{CaCl}_{2}$.

Biosynthesis and Analysis of 12-LO and COX-1 Products. The isolated platelets were preincubated $\left(10^{8}\right.$ cells $\left./ \mathrm{ml}\right)$ with the<smiles>O=c1cc(-c2ccccc2)oc2cc(O)c(O)c(O)c12</smiles><smiles>O=c1cc(-c2ccc(O)cc2)oc2cc(O)cc(O)c12</smiles><smiles>O=C(/C=C/c1ccc(O)c(O)c1)OCCc1ccccc1</smiles><smiles>O=c1c(O)c(-c2ccc(O)c(O)c2)oc2cc(O)cc(O)c12</smiles>

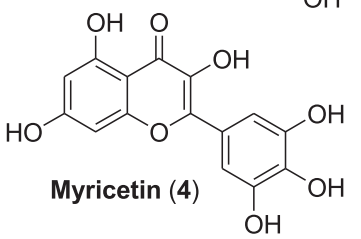

Fig. 1. Structures of flavones [baicalein (compound 1) and apigenin (compound 2)], 3-hydroxyflavones [quercetin (compound 3) and myricetin (compound 4)], and CAPE (compound 5). 
<smiles></smiles><smiles>COc1cc(OC)c2c(=O)c(OC)c(-c3ccc(OC)c(OC)c3)oc2c1</smiles>

Fig. 2. Structures of acetylated and methylated quercetin analogs (compounds 6-8). various compounds [or dimethylsulfoxide (DMSO) as the control] at $37^{\circ} \mathrm{C}$ for 5 minutes. Stimulation was then initiated with the addition of $0.5 \mathrm{U} / \mathrm{ml}$ of thrombin (Sigma-Aldrich, Oakville, ON) and $10 \mu \mathrm{M}$ of exogenous arachidonic acid (Cayman Chemical, Ann Arbor, MI) followed by 15 minute incubation at $37^{\circ} \mathrm{C}$. The reactions were stopped with the addition of three volumes of cold $\mathrm{MeOH}: \mathrm{MeCN}$ (1:1) containing prostaglandin $\mathrm{B}_{2}\left[\left(\mathrm{PGB}_{2}\right), 100 \mathrm{ng} / \mathrm{ml}\right]$ as the internal standard. Samples were then stored at $-20^{\circ} \mathrm{C}$ overnight and centrifuged at $300 \mathrm{~g}$ the following day to collect the supernatant containing $12-\mathrm{LO}$ and COX-1 products. The supernatant was then evaporated under nitrogen gas and the sample was resuspended in $30 \%(\mathrm{v} / \mathrm{v})$ methanol and analyzed by reversed-phase high-performance liquid chromatography (RP-HPLC), as previously described (Robichaud et al., 2016; Boudreau et al., 2017). Briefly, samples were injected onto an Agilent 1100 HPLC equipped with an Oasis HLB online cartridge column $(3.9 \times 20 \mathrm{~mm}$, $15 \mu \mathrm{m}$ particle size; Waters, Milford, MA) for in-line extraction using $0.1 \%$ acetic acid as the mobile phase at a flow rate of $3 \mathrm{ml} / \mathrm{min}$ for 3 minutes. The solvent was then changed over 0.1 minute to solvent $\mathrm{A}$ (54\% water: $23 \%$ methanol, $23 \%$ acetonitrile, and $0.0025 \% \mathrm{H}_{3} \mathrm{PO}_{4}$ ), and a Rheodyne valve was switched to direct the flow to a Chromolith High Resolution RP-18 end-capped column $(100 \times 4.6 \mathrm{~mm})$ (EMD Millipore, Burlington, MA) at a flow rate of $2.2 \mathrm{ml} / \mathrm{min}$. After 5.11 minutes, the mobile phase was then changed to $85 \%$ solvent $A$ and $15 \%$ solvent $\mathrm{B}\left(5 \%\right.$ water, $32 \%$ methanol, $63 \%$ acetonitrile, and $\left.0.01 \% \mathrm{H}_{3} \mathrm{PO}_{4}\right)$ for 1 minute, followed by a linear gradient to $55 \%$ solvent $\mathrm{A}$ and $45 \%$ solvent B over the next 0.3 minutes and held at that proportion for an additional 1.3 minutes. The gradient was then changed in a linear fashion to $30 \%$ solvent $\mathrm{A}$ and $70 \%$ solvent $\mathrm{B}$ over a 1.3-minute period and held for an additional 1.3 minutes at which time the mobile phase was changed to $100 \%$ solvent $\mathrm{B}$ over 0.2 minutes and held for 3.5 minutes. Peaks were quantified by absorbance at 236 and $270 \mathrm{~nm}$ using a diode array detector.

Biosynthesis of 5-LO Products in Human Embryonic Kidney 293 Cells. Human embryonic kidney 293 (HEK293) cells expressing both 5-LO and the 5-LO activating protein were generated by stable transfection as previously reported (Allain et al., 2015). For 5-LO product analysis, stably transfected HEK293 cells were collected following trypsinization and washed twice with Hanks' balanced salt solution (Lonza, Basel, Switzerland). Subsequently, the cell pellet was resuspended in Hanks' balanced salt solution containing $1.6 \mathrm{mM}$ $\mathrm{CaCl}_{2}$ at a concentration of $10^{6}$ cells $/ \mathrm{ml}$. Cells were preincubated with each compound at $1 \mu \mathrm{M}$ for 5 minutes at $37^{\circ} \mathrm{C}$ prior to stimulation for 15 minutes at $37^{\circ} \mathrm{C}$ with the addition of $10 \mu \mathrm{M}$ calcium ionophore A23187 (Sigma-Aldrich) and $40 \mu \mathrm{M}$ arachidonic acid (Cayman Chemical) (Gerstmeier et al., 2014; Allain et al., 2015; Boudreau et al., 2017). Stimulations were stopped by adding 0.5 volume of cold $\mathrm{MeOH}$ : MeCN (1:1) containing $100 \mathrm{ng} / \mathrm{ml}$ of $\mathrm{PGB}_{2}$ as internal standard. Samples were then processed, and 5-LO products were quantified by RP-HPLC, as described previously in Biosynthesis and Analysis of 12-LO and COX-1 Products.

Polymorphonuclear Leukocyte Stimulation for Analysis of 5-LO Product Biosynthesis. Human polymorphonuclear leukocytes
(PMNLs) were isolated from peripheral blood as previously described (Chouinard et al., 2013). Briefly, blood was centrifuged (250g for 17 minutes) to remove the platelet-rich plasma. Following sedimentation of erythrocytes with $6 \%$ dextran, mononuclear cells were discarded by centrifugation on a discontinuous gradient using lymphocyte separation medium cushions. Residual erythrocytes were then eliminated from the PMNL pellet by hypotonic lysis using water.

For stimulation of 5-LO product biosynthesis, PMNLs were prewarmed at $37^{\circ} \mathrm{C}$ in a suspension of Hanks' balanced salt solution containing $1.6 \mathrm{mM} \mathrm{CaCl}{ }_{2}$ at $10^{7}$ cells $/ \mathrm{ml}$. Adenosine deaminase ( $0.3 \mathrm{U} / \mathrm{ml}$; Sigma-Aldrich) was added to cells 10 minutes prior to stimulation to eliminate the inhibitory effects of extracellular adenosine (Krump et al., 1997). PMNLs were also preincubated for 5 minutes with different concentrations of zileuton, baicalein (compound 1), quercetin (compound 3), and compound 6. The 5-LO product biosynthesis was initiated with the addition of $1 \mu \mathrm{M}$ thapsigargin and $10 \mu \mathrm{M}$ arachidonic acid. After 15 minutes, incubations were stopped with the addition of 0.5 volume of cold stop solution $(\mathrm{MeOH} / \mathrm{MeCN}$; $1 / 1 ; \mathrm{v} / \mathrm{v}$ ) containing $19-\mathrm{OH}-\mathrm{PGB}_{2}$ and $\mathrm{PGB}_{2}$ as internal controls and then transferred to a cold water bath. Finally, samples were stored at $-20^{\circ} \mathrm{C}$ overnight to facilitate protein precipitation until RP-HPLC analysis as described in Biosynthesis and Analysis of 12-LO and COX-1 Products.

Measurement of Arachidonic Acid Release. Isolated platelets $\left(10^{7}\right.$ cells $\left./ \mathrm{ml}\right)$ were incubated at $37^{\circ} \mathrm{C}$ for 5 minutes and then stimulated with thrombin $(0.5 \mathrm{U} / \mathrm{ml})$ as described previously. Reaction was stopped after 5 minutes by the addition of two volumes of cold methanol containing $300 \mathrm{ng}$ of octadeuterated arachidonic acid (Cayman Chemical) as an internal standard. Samples were stored at $-20^{\circ} \mathrm{C}$ overnight and centrifuged at $1000 \mathrm{~g}$ for 10 minutes. Supernatants were diluted with eight volumes of acidified water for processing on preconditioned HyperSep C18 solid phase extraction cartridges (Thermo Fisher Scientific, Waltham, MA). Samples were washed with $2 \mathrm{ml}$ of acidified water and eluted with $3 \mathrm{ml}$ of methanol, dried under $\mathrm{N}_{2}$ gas, and pentafluorobenzylesters were prepared by adding $50 \mu \mathrm{l}$ of $N, N$-diisopropylethylamine $\left(20 \%\right.$ in $\mathrm{CH}_{3} \mathrm{CN}$ ) (SigmaAldrich) and $50 \mu \mathrm{l}$ of 2,3,4,5,6-pentafluorobenzyl bromide (20\% in $\mathrm{CH}_{3} \mathrm{CN}$ ) (Sigma-Aldrich) (Surette et al., 1996; Boudreau et al., 2012). Solutions were heated at $40^{\circ} \mathrm{C}$ for 40 minutes, dried under $\mathrm{N}_{2}$ gas, resuspended in $100 \mu \mathrm{l}$ hexane, and pentafluorobenzyl esters were analyzed by gas chromatography/mass spectrometry using a Thermo Trace GC equipped with a BPX70 column (SGE Analytical Science, Austin, TX) coupled to a Polaris Q mass spectrometer (Thermo Fisher Scientific). Injector temperature was set to $250^{\circ} \mathrm{C}$ with helium carrier gas at $1 \mathrm{ml} / \mathrm{min}$. Oven temperature on injection was set to $185^{\circ} \mathrm{C}$ and ramped to $205^{\circ} \mathrm{C}$ at $3^{\circ} \mathrm{C} / \mathrm{min}$ followed by a ramp to $255^{\circ} \mathrm{C}$ at $5^{\circ} \mathrm{C} / \mathrm{min}$ with a 2-minute hold. Ions were generated by negative chemical ionization using methane $(1.0 \mathrm{ml} / \mathrm{min})$ as the reagent gas, with the ion source temperature set to $180^{\circ} \mathrm{C}$, and helium damping gas $(0.3 \mathrm{ml} / \mathrm{min})$. Arachidonic acid and octadeuterated arachidonic acid were identified according to their respective retention times and molar masses (as carboxylates). 
Free Radical Scavenging Activity. The free radical scavenging activity of the test compounds was assessed by 2,2-diphenyl-1picrylhydrazyl (DPPH) free radical assay as previously described (Boudreau et al., 2012; Doiron et al., 2014). Samples (powder form) were first resuspended in ethanol, and then mixed with the stable free radical DPPH in an ethanol solution. The mixture was prepared by mixing $200 \mu \mathrm{l}$ of the ethanol DPPH solution $(250 \mu \mathrm{M})$ with $200 \mu \mathrm{l}$ of the test compound (ethanol as diluent) at the indicated concentration. Each tube's content was shaken vigorously, held in the dark for 30 minutes, and the absorbance was subsequently measured at $517 \mathrm{~nm}$ with a multiplate reader (Thermo Fisher Scientific VarioSkan spectrophotometer). DPPH solution in ethanol served as the control, and ethanol as a blank. The radical scavenging activity of the test compounds was calculated using the following formula,

$$
\% \text { Inhibition }=\left\{\left[\left(A_{\text {control }}-A_{\text {test }}\right) / A_{\text {control }}\right]\right\} \times 100
$$

where $A_{\text {control }}$ is the absorbance of the control and $A_{\text {test }}$ is the absorbance of the test compound.

Platelet Activation. Platelets were isolated as mentioned previously and immediately preincubated $\left(10^{8}\right.$ cells $\left./ \mathrm{ml}\right)$ in the presence of the various compounds $\left(10 \mu \mathrm{M}\right.$ or $\mathrm{DMSO}$ as control) at $37^{\circ} \mathrm{C}$ for 5 minutes. To determine if the test compounds activated the platelets, each sample $(1 \mu \mathrm{l})$ was then labeled with $1 \mu \mathrm{l}$ of FITC anti-human CD62P (P-Selectin; BioLegend, San Diego, CA) in $98 \mu$ l of phosphatebuffered solution (Lonza) for 15 minutes in the dark. After the incubation, $500 \mu \mathrm{l}$ of phosphate-buffered solution was added to each sample. Platelets labeled with anti-CD62P but incubated in the absence of DMSO (Sigma-Aldrich) were tested as a no-activation control. Autofluorescence and isotype controls were done using a pooled sample. Positive control was obtained after incubating platelets for 15 minutes in the presence of $0.5 \mathrm{U} / \mathrm{ml}$ of thrombin. Samples were then processed for flow cytometry analysis (FC500; Beckman Coulter, Brea, CA).

Molecular Docking. The molecular docking protocol was adapted from Nuñez et al. (2017). The studied compounds where docked into multiple crystal structures of five different lipoxygenases, see Table 1, with the help of Autodock Vina (Trott and Olson, 2010). Autodock Vina was also used to calculate the affinities of the molecules. It should be noted that while a structure of human 12-LO [Protein Data Bank (PDB) id: 3D3L; https://www.rcsb.org] is available, around 90 residues are missing per chain, including important residues for the active site. Because of this, a soybean 15-secondLOX (15-LO) (lipoxygenase-3, PDB: $1 \mathrm{~N} 8 \mathrm{Q}$ ) was taken as the main protein for study since it is considered acceptable for 12-LO and 15-LO studies (Wecksler et al., 2009; Nuñez et al., 2017). The other proteins were mostly used as validation for the usage of the 15 -secondLOX. The histidine residues coordinating the iron atom were considered flexible. Before docking, the compounds were minimized with the MMFF94 force field. The configuration for the docking was as follows: all proteins had their water deleted and structures aligned to $3 \mathrm{O} 8 \mathrm{Y}$; the grid had a size of $(30,20,30)$ and the center was positioned at $(4.049,21.347,-0.284)$, both represented in $(x, y, z)$; and exhaustiveness was set to " 8 " and the seed was set to "1." For $1 \mathrm{~N} 8 \mathrm{Q}$, specifically with baicalein (compound $\mathbf{1}$ ) and CAPE (compound 5), a revised grid of $(19,14,21)$ and a center point of $(-0.4,25.58,-2.49)$ was chosen. Analysis and generation of images was done with the help of Maestro and LigPlot+ (Laskowski and Swindells, 2011).

High-Resolution Respirometry. Mitochondrial oxygen consumption of platelets was assessed using a high-resolution respirometer (Oxygraph-2k; Oroboros Instruments, Innsbruck, Austria) as previously described (Bynum et al., 2016). Briefly, platelets were isolated as mentioned previously and resuspended at $10^{8} \mathrm{cell} / \mathrm{ml}$ in mitochondrial respiration medium MiR05 (0.5 mM EGTA, $3 \mathrm{mM} \mathrm{MgCl} 2,60 \mathrm{mM}$

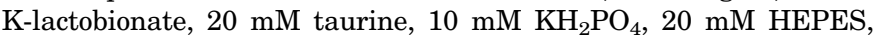
$110 \mathrm{mM}$ D-sucrose, and $1 \mathrm{~g} / \mathrm{l}$ bovine serum albumin, $\mathrm{pH}$ 7.1) (Gnaiger and Kuznetsov, 2002).

After air-saturation oxygen calibration at $37^{\circ} \mathrm{C}$ was performed, platelets were added in the oxygraph. The routine respiration (or basal) was determined as the basal state of mitochondrial oxygen consumption. Injection of the different compounds $(15 \mu \mathrm{M})$ or DMSO (control) into the oxygraph was then performed, before the leak state was obtained by inhibiting complex V with $2 \mu \mathrm{l} / \mathrm{ml}$ Oligomycin (Sigma-Aldrich). Serial titrations using the uncoupler carbonyl cyanide- $p$-trifluoromethoxyphenylgydrazone ( $1 \mu \mathrm{M}$ steps; Sigma-Aldrich) were then performed to determine the maximal $\mathrm{O}_{2}$ consumption/electron transport system (ETS) capacity. Subsequently, rotenone (0.1 $\mu \mathrm{M}$; Sigma-Aldrich) and antimycin A (2.5 $\mu \mathrm{M}$; SigmaAldrich) were added to respectively inhibit complexes I and III, and thus determine the residual oxygen consumption, which corresponds to nonmitochondrial oxidative side reactions. The residual oxygen consumption value was subtracted from the previous mitochondrial respiration rates (Pesta and Gnaiger, 2012). From these corrected respiration rates, the ETS coupling efficiency (i.e., 1 - leak/ETS) was used as a control ratio, representative of the mitochondrial coupling. An ETS coupling efficiency of 0.0 expresses a zero coupling (leak = ETS) and 1.0 is the limit of a fully coupled system (leak $=0$ ) (Gnaiger, 2012).

Statistical Analysis. Data, graphics, and tables are presented as mean \pm S.D. Data were analyzed using GraphPad Prism software (version 7.0; GraphPad Software Inc., La Jolla, CA). The IC $_{50}$ values were calculated from a sigmoidal concentration-response curvefitting model and are expressed as the mean with $95 \%$ confidence intervals. All other data are expressed as mean \pm S.D. One-way analyses of variance with the indicated multiple comparisons test were performed on completely randomized designs to determine a significant difference.

\section{Results}

Inhibition of Platelet-Type 12(S)-HETE Biosynthesis. In the first series of experiments, we performed a screening of flavonoid compounds as potential inhibitors of the 12-LO pathway. Freshly isolated human platelets were preincubated in the presence of the indicated compound or vehicle (DMSO), and then stimulated with thrombin $(0.5 \mathrm{U} / \mathrm{ml})$ and exogenous arachidonic acid $(10 \mu \mathrm{M})$ to initiate $12(\mathrm{~S})$-HETE biosynthesis as previously described (Boudreau et al., 2017). By adding exogenous arachidonic acid in our experimental design, we eliminated the constraint that our compounds may impact arachidonic acid release from cell membranes (Rossi et al., 2010;

TABLE 1

Molecular docking of tested compounds with various lipoxygenase

\begin{tabular}{lclc}
\hline \multicolumn{1}{c}{ Protein } & PDB ID & \multicolumn{1}{c}{ Organism } & Resolution \\
\hline & & & $\AA$ \\
Lipoxygenase-3 (LO1.3) & 1N8Q & Glycine max (soybean) & 2.1 \\
Arachidonate 15-lipoxygenase (15-LO) & 2P0M & Oryctolagus cuniculus (rabbit) & 2.4 \\
Arachidonate 12-lipoxygenase (12S-LO) & 3D3L & Homo sapiens (human) & 2.6 \\
Arachidonate 5-lipoxygenase (5-LO) & 3O8Y & Homo sapiens (human) & 2.389 \\
Arachidonate 15-lipoxygenase B (15-LO-B) & 4NRE & Homo sapiens (human) & 2.63 \\
\hline
\end{tabular}


Boudreau et al., 2012), thus decreasing the substrate availability in platelets. Of all the compounds tested, quercetin (compound 3), a quercetin derivative (compound 6), baicalein (compound 1), and CAPE (compound 5) significantly inhibited 12(S)-HETE production at $1 \mu \mathrm{M}$ (Fig. 3A). Based on the fact that the primary objective of this study was to identify selective inhibitors of the 12-LO pathway, only these compounds were selected for subsequent characterization.

We then performed a series of dose-response experiments in human platelets to determine the $\mathrm{IC}_{50}$ values associated with each compound. All compounds had low $\mathrm{IC}_{50}$ values; however, none of the compounds tested were significantly more potent than another (Fig. 3B; Table 2). These results demonstrate that quercetin and its derivative, compound $\mathbf{6}$, are potent inhibitors of the $12(S)$-HETE pathway with similar potency as our reference compounds, baicalein (compound 1) and CAPE (compound 5).

Inhibition of COX-1 Product Biosynthesis in Platelets. Having confirmed that baicalein (compound 1), quercetin
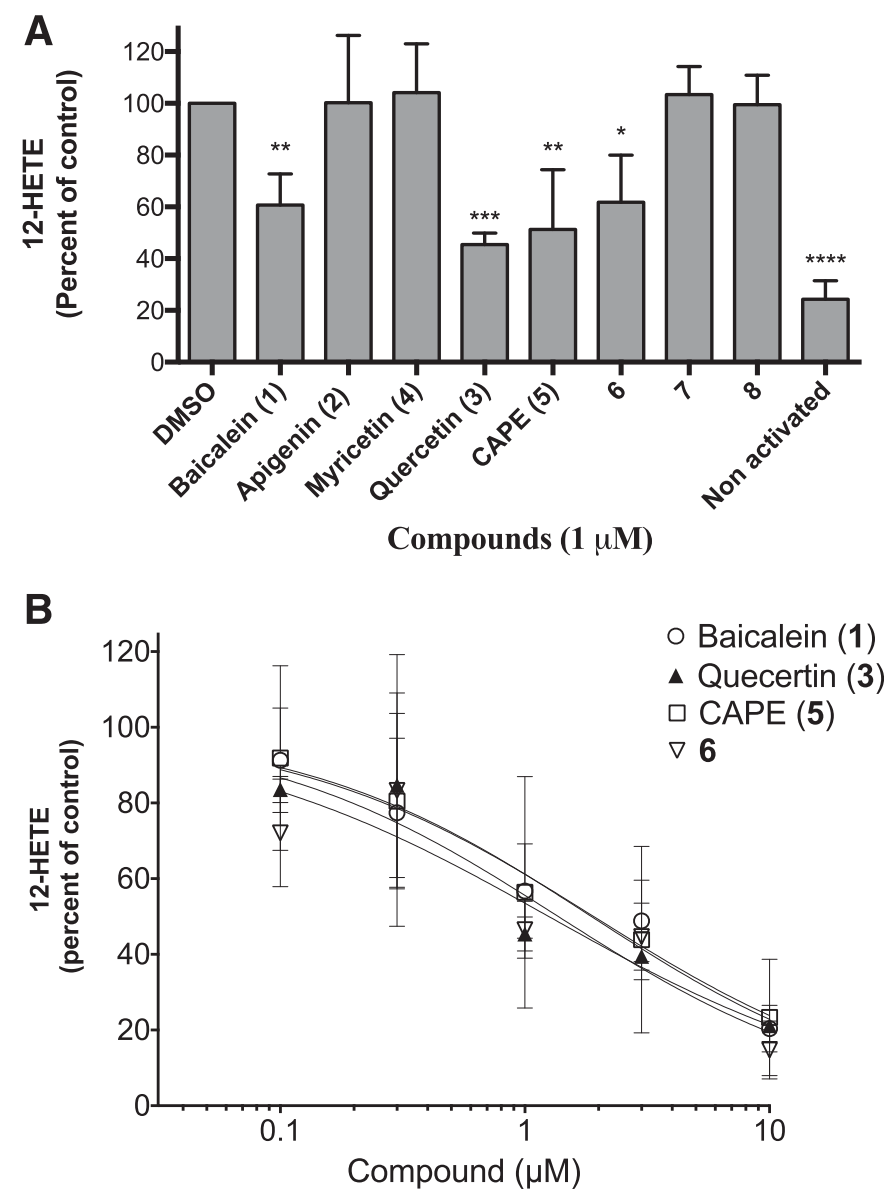

Fig. 3. Inhibition of the $12(S)$-HETE biosynthesis in human platelets. Human platelets were isolated from blood and preincubated with the indicated compound at $37^{\circ} \mathrm{C}$ for 5 minutes. Cells were then stimulated with thrombin $(0.5 \mathrm{U} / \mathrm{ml})$ and arachidonic acid $(10 \mu \mathrm{M})$ at $37^{\circ} \mathrm{C}$ for 15 minutes. RP-HPLC quantification of the 12-LO product [12(S)-HETE] was performed as previously described (Boudreau et al., 2017). (A) Initial screening of compounds $(1 \mu \mathrm{M})$ and (B) subsequent dose-response experiments for compounds demonstrating 12-LO product biosynthesis inhibition higher than $40 \%$ of control (DMSO). Results are expressed as the mean \pm S.D. of three independent experiments, each performed in duplicate. Values are statistically different from DMSO control ( ${ }^{*} P<0.05$; ${ }^{* *} P<0.01 ; * * * P<0.001 ; * * * * P<0.0001$ ) as determined by one-way analysis of variance followed by Dunnett's multiple comparisons test.
TABLE 2

Calculated $\mathrm{IC}_{50}$ values of selected compounds for the inhibition of 12-LO product biosynthesis in human platelets

Values are the mean $\pm 95 \%$ confidence interval from at least three independent experiments.

\begin{tabular}{lcc}
\hline \multicolumn{1}{c}{ Compound } & $\mathrm{IC}_{50}(95 \% \mathrm{CI})$ & Sample Size \\
\hline & $\mu M$ & \\
Baicalein (compound 1) & $1.78(1.25-2.54)$ & 4 \\
Quercetin (compound 3) & $1.34(0.92-1.95)$ & 3 \\
CAPE (compound 5) & $1.28(0.69-2.39)$ & 4 \\
Compound 6 & $1.53(0.78-3.01)$ & 3 \\
\hline
\end{tabular}

CI, confidence interval.

(compound 3), CAPE (compound 5), and compound 6 inhibited 12(S)-HETE biosynthesis, we then evaluated whether other platelet-derived eicosanoid inflammatory pathways could be targeted by our compounds. An important eicosanoid metabolite abundantly produced by platelets is thromboxane $\mathrm{A}_{2}$, a potent stimulator of platelet aggregation (Narumiya, 2003), generated via the COX-1 pathway. While thromboxane $\mathrm{A}_{2}$ cannot be quantified by standard RP-HPLC methods, measurement of 12-hydroxyheptadecatrienoic acid (12-HHT), which is produced in equimolar quantities with thromboxane $\mathrm{A}_{2}$, can be used for the quantification of platelet-derived COX products by RP-HPLC (Okuno et al., 2008). Freshly isolated platelets were preincubated at various concentrations of test compounds, and then 12-HHT biosynthesis was initiated with the addition of thrombin $(0.5 \mathrm{U} / \mathrm{ml})$ and exogenous arachidonic acid $(10 \mu \mathrm{M})$. Interestingly, compound 6 was the only molecule for which an $\mathrm{IC}_{50}$ value could not be obtained at the tested concentrations. On the other hand, baicalein (compound 1), quercetin (compound 3), and CAPE (compound 5) all inhibited 12-HHT biosynthesis with $\mathrm{IC}_{50}$ values in the low micromolar range at doses of 9.92, 2.91, and $3.79 \mu \mathrm{M}$, respectively (Fig. 4; Table 3). These results demonstrate the selectivity of compound 6 for the 12(S)-HETE biosynthesis pathway in human platelets when compared with the other test compounds, including the well-known 12-LO inhibitor baicalein (compound $\mathbf{1}$ ).

Arachidonic Acid Release. Having established that compound 6 is a more selective inhibitor of the 12-LO pathway in human platelets than the other compounds tested in this study, we then investigated the potential underlying mechanisms. Since flavonoids and other lipoxygenase inhibitors have shown some ability to inhibit the release of arachidonic acid from the cellular membranes in human PMNLs (Rossi et al., 2010; Boudreau et al., 2012, 2017; Meirer et al., 2014), we evaluated whether compound $\mathbf{6}$ could also interfere with arachidonic acid release in human platelets, thus limiting the cellular production of $12(\mathrm{~S})$-HETE. Interestingly, we found that each of our tested compounds did not interfere with arachidonic acid release in human platelets (Fig. 5). These results suggest that, in human platelets, compound 6 does not limit the substrate availability for the 12-LO pathway. In all experiments, the range of arachidonic acid:octadeuterated arachidonic acid isotope dilutions was from 0.2:1 to 0.01:1.

Free Radical Scavenging Assay. Having confirmed that our compounds do not affect arachidonic acid release in platelets, another possible mechanism involved in the inhibitory effect of compound $\mathbf{6}$ could be attributed to superior antioxidant capacities. Since $12-\mathrm{LO}$ catalyzes the oxidation of the 12th carbon on the arachidonic acid, any compound with 


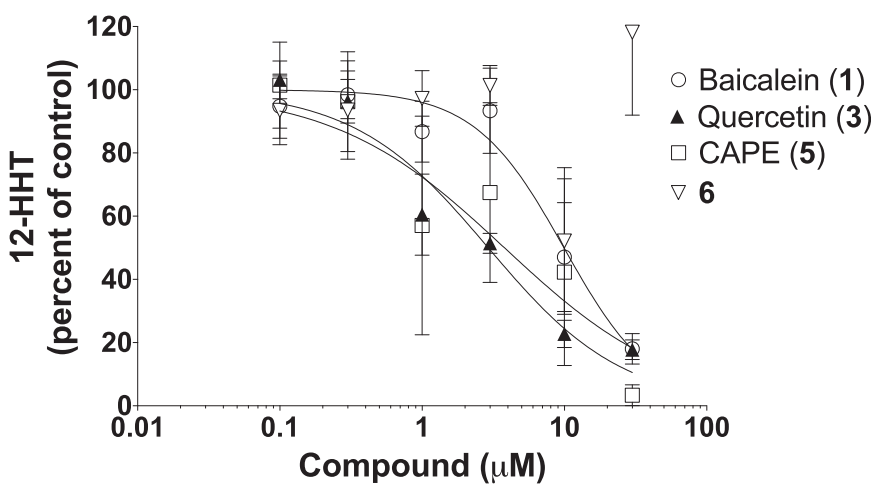

Fig. 4. Inhibition of COX-1 product biosynthesis in platelets. Human platelets were isolated from blood and preincubated with the indicated compounds at $37^{\circ} \mathrm{C}$ for 5 minutes for dose-response experiments. Cells were then stimulated with thrombin $(0.5 \mathrm{U} / \mathrm{ml})$ and arachidonic acid $(10 \mu \mathrm{M})$ at $37^{\circ} \mathrm{C}$ for 15 minutes. RP-HPLC quantification of the COX-1 product, 12-HHT, was performed as previously described (Boudreau et al., 2017). Results are expressed as the mean \pm S.D. of three independent experiments, each performed in duplicate.

antioxidant properties could interfere in $12(S)$-HETE biosynthesis, which is the case for baicalein (compound 1) (Lapchak et al., 2007). However, as shown in Fig. 6 and Table 4, compound 6 was the only tested compound without significant free radical scavenging capacity at the tested concentration. In contrast, baicalein (compound 1), quercetin (compound 3), and the well-known antioxidant compound ascorbic acid were potent free radical scavengers. These results indicate that compound 6 does not exhibit antioxidant properties at the tested concentrations.

Molecular Docking. Having confirmed that compound 6 does not interfere with the oxidant activity of the 12-LO enzyme, we investigated whether this compound directly interacts with the enzyme. Molecular docking was completed on the five proteins with the ligands listed in Table 1. In general, the soybean 15-LO-B (PDB: 1N8Q) had the largest affinity values of the five proteins tested. For the five tested molecules, the average affinity was $0.3 \mathrm{kcal} / \mathrm{mol}$. CAPE (compound 5) had the lowest affinity with $-5.4 \mathrm{kcal} / \mathrm{mol}$ (Table 5), although it had slightly better affinity with the remaining four proteins, with average values of approximately $-8.3 \mathrm{kcal} / \mathrm{mol}$. Of the tested molecules, CAPE (compound 5) averaged the best affinity across the five proteins. As seen in Table 5, CAPE (compound $\mathbf{5}$ ) had four hydrogen bonds with soybean LO (PDB: 1N8Q), 2 with Ser510 and 2 with Arg426. CAPE (compound 5) also had $\pi$ - $\pi$ interactions with His518 and Phe576, as was the case with most of the other tested molecules.

TABLE 3

Calculated $\mathrm{IC}_{50}$ values of selected compounds for the inhibition of COX-1 product biosynthesis in human platelets

Values are the mean $\pm 95 \%$ confidence interval from at least three independent experiments.

\begin{tabular}{lcc}
\hline \multicolumn{1}{c}{ Compound } & $\mathrm{IC}_{50}(95 \% \mathrm{CI})$ & Sample Size \\
\hline & $\mu M$ & \\
Baicalein (compound 1) & $9.92(7.41-13.28)$ & 4 \\
Quercetin (compound 3) & $2.91(2.11-4.03)$ & 3 \\
CAPE (compound 5) & $3.79(1.60-8.97)$ & 4 \\
Compound 6 & N.D. & 3
\end{tabular}

CI, confidence interval; N.D., values not determined at tested concentrations.

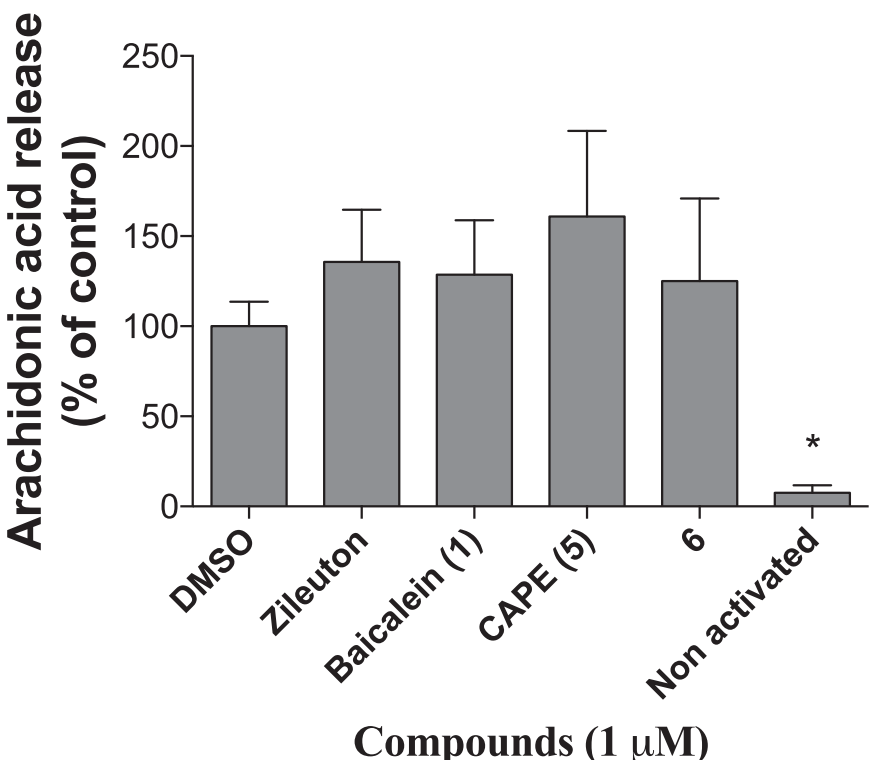

Fig. 5. Effects of compounds on arachidonic acid release in platelets. Human platelets were isolated from human blood of healthy consenting volunteers and preincubated with the indicated compounds at $37^{\circ} \mathrm{C}$ for 5 minutes. Cells were then stimulated with thrombin $(0.5 \mathrm{U} / \mathrm{ml})$ at $37^{\circ} \mathrm{C}$ for 5 minutes. Reaction was stopped with the addition of two volumes of cold methanol containing octadeuterated arachidonic acid as an internal standard and processed by gas chromatography/mass spectrometry as previously described (Boudreau et al., 2012). Results are expressed as the mean \pm S.D. of three independent experiments, each performed in duplicate. The total free arachidonic acid level for the DMSO control represents $52.9 \mathrm{ng}$ of arachidonic acid per $5 \times 10^{7}$ platelets. Values are statistically different from DMSO control $(* P<0.05)$ as determined by one-way analysis of variance followed by Dunnett's multiple comparisons test.

The compound 6 is an interesting case. With 15-LO-B (PDB: $1 \mathrm{~N} 8 \mathrm{Q}$ ), it scored the highest affinity with $8.8 \mathrm{kcal} / \mathrm{mol}$, while simultaneously scoring the lowest affinity with $-8.8 \mathrm{kcal} / \mathrm{mol}$ for 12S-LO (PDB ID: 3D3L) and having a subpar affinity for the remaining proteins. It did a hydrogen bond similar to that

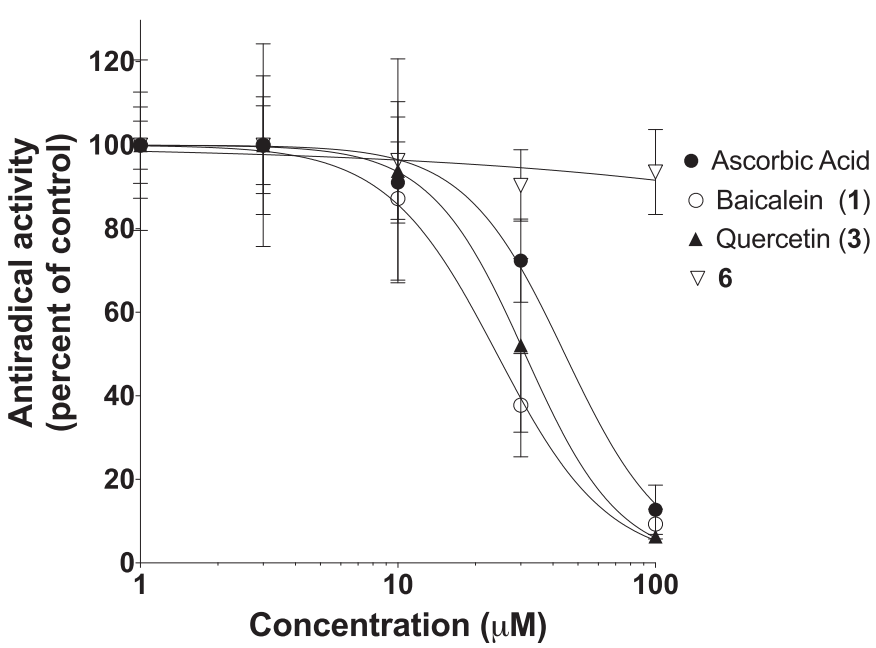

Fig. 6. Free radical scavenging activity. The free radical scavenging capacity of test compounds was assessed using DPPH as a stable free radical. Samples were mixed with the stable DPPH in ethanol. Test compounds at indicated concentrations were added to the DPPH solution and solutions were held in the dark for 30 minutes at room temperature. Absorbance was subsequently measured at $517 \mathrm{~nm}$. The free radical scavenging activity was expressed in terms of percentage of inhibition of the DPPH absorbance. Values represent the mean \pm S.D. of three independent experiments, each performed in triplicate. 
TABLE 4

Calculated $\mathrm{IC}_{50}$ values of selected compounds as free radical scavengers Values are the mean from three independent experiments, each performed in duplicate.

\begin{tabular}{lc}
\hline \multicolumn{1}{c}{ Compound } & $\mathrm{IC}_{50}(95 \% \mathrm{CI})$ \\
\hline & $\mu M$ \\
Ascorbic acid & $44.5(36.6-54.1)$ \\
Baicalein (compound 1) & $24.3(18.8-31.3)$ \\
Quercetin (compound 3) & $31.2(21.5-45.1)$ \\
Compound 6 & N.I. \\
\hline
\end{tabular}

CI, confidence interval; N.I., no inhibition at $100 \mu \mathrm{M}$.

of CAPE (compound 5) with Ser510, but no hydrogen bonds with Arg426 or $\pi-\pi$ interactions were detected.

While most tested molecules were within reach of interaction with the iron atom, requiring a small shift, only baicalein (compound 1) had the characteristic of directly interacting with the iron atom. They also took very similar poses, almost superimposing with each other (root-mean-square deviation $=0.42$ ).

Most ligands generally seemed to interact similarly across the various proteins. This may help confirm that the soybean 15-LO-B (PDB: 1N8Q) crystal may be helpful in studying human 12-LO until a better crystal is available. One major exception was again compound 6 with 15-LO (PDB ID: 2P0M). Compound 6 was outside the active site, positioning itself outside the cavity.

Inhibition of 5-Lipoxygenase Product Biosynthesis. Having identified compound $\mathbf{6}$ as a modulator of the 12-LO's ability to convert arachidonic acid into $12(S)$-HETE, we then sought to further evaluate the compound's selectivity by investigating its capacity to inhibit the 5-LO pathway in stably transfected HEK293 cells and human PMNLs. Compounds CAPE (compound 5) and zileuton were used as reference molecules since both are potent 5-LO inhibitors (Liu et al., 1996; Boudreau et al., 2012; Hofmann and Steinhilber, 2013). Stably transfected HEK293 were first preincubated in the presence of the indicated compounds at $1 \mu \mathrm{M}$ prior to stimulation. Compounds 6, quercetin (compound 3), baicalein (compound 1), CAPE (compound 5), and zileuton significantly inhibited product biosynthesis when compared with the vehicle (DMSO, Fig. 7). While compound 6 inhibited 5-LO product biosynthesis in HEK293 cells, its inhibitory activity was less potent than that of the reference compounds CAPE (compound 5) and zileuton.

We also investigated our compounds' potency in a more physiologic environment. Using human PMNLs, we found that 5-LO product biosynthesis was inhibited by compounds zileuton, baicalein (compound 1), quercetin (compound 3), and compound 6 with $\mathrm{IC}_{50}$ values of $2.07,11,2.96$, and $2.83 \mu \mathrm{M}$, respectively (Fig. 8; Table 6 ).
High-Resolution Respirometry in Platelets. Having demonstrated that compound $\mathbf{6}$ is an inhibitor of the 12-LO pathway, we investigated whether our compounds had offtarget effects on normal cellular functions. In the first series of experiments, we investigated whether the compounds affected the overall cellular respiration, i.e., mitochondrial oxygen consumption during different conditions such as the Basal respiration, leak respiration, and maximal ETS capacity (see Supplemental Fig. 1). The different respiration rates of platelets exposed to DMSO (control) or to the five compounds of interest are represented in Fig. 9. Respiration rates (basal, leak, and ETS capacity) were not affected by treatments with the indicated compounds (Fig. 9). However, it is interesting to underline that DMSO and quercetin (compound 3) had the same effect on the mitochondrial respiration of platelets, displaying very similar values (mean difference: $0.012 ; 95 \%$ CI: -0.41 to 0.43 ; adjusted $P>0.999$ ). Having demonstrated that our compounds did not affect the respiratory phenotype of the cell, we investigated whether the same compounds could modulate $\mathrm{P}$-selectin (CD62P) surface expression, a typical marker of platelet activation (Murakami et al., 1996). As shown in Fig. 10, the test compounds had no effect on P-selectin surface expression when compared with control ( $0.1 \%$ DMSO). These results suggest that our tested compounds did not affect the degree of platelet activation.

\section{Discussion}

The eicosanoid $12(S)$-HETE, generated via the 12-LO pathway, remains one of the most underappreciated lipid mediators of inflammation (Porro et al., 2014). As a proinflammatory lipid mediator, 12(S)-HETE has been shown to promote vasodilation (Faraci et al., 2001) and promote cell-derived microvesicle internalization in PMNLs (Duchez et al., 2015). In addition, 12(S)-HETE actively participates in several types of inflammatory diseases including cancer (Ding et al., 2001; Nguyen et al., 2016), atherosclerosis (Cyrus et al., 1999), and arthritis (Duchez et al., 2015). Among the compounds that have generated interest in the field of eicosanoid regulation, which includes $12(S)$-HETE, are the naturally occurring polyphenols including the flavonoids, a class of bioactive plant compounds that exhibits several beneficial properties (Werz, 2007; Boudreau et al., 2012, 2017; Macready et al., 2014). These studies have shown that flavonoids and some newly designed structural analogs can decrease the production of inflammatory lipid mediators by inhibiting inflammatory enzyme pathways (Sekiya and Okuda, 1982; Werz, 2007; Ribeiro et al., 2015). In the first part of this study, we examined whether the distribution of hydroxyl groups among flavones could influence their potency as 12-LO inhibitors

TABLE 5

Affinity and interactions of molecular modeling with a soybean 15-LO (lipoxygenase-3, PDB ID: 1N8Q)

\begin{tabular}{|c|c|c|c|c|}
\hline \multirow{2}{*}{ Molecule } & \multirow{2}{*}{ Affinity } & \multicolumn{2}{|c|}{ Ligplot+ } & \multirow{2}{*}{$\begin{array}{l}\text { Maestro } \pi-\pi \\
\text { Interaction }\end{array}$} \\
\hline & & Hydrogen Bond & Hydrogen Bond Length & \\
\hline & $\mathrm{kcal} / \mathrm{mol}$ & & $\AA$ & \\
\hline Baicalein (compound 1) & -1.4 & $\mathrm{Fe}$ & 3.33 & His518, Phe576 \\
\hline Quercetin (compound 3) & 0.8 & Asp766 & 2.82 & His518, Phe576 \\
\hline CAPE (compound 5) & -5.4 & $\operatorname{Arg} 426 \times 2, \operatorname{Ser} 510 \times 2$ & $2.78,3.23,2.90,3.18$ & His518, Phe576 \\
\hline Compound 6 & 8.8 & Ser510 & 2.66 & None \\
\hline
\end{tabular}




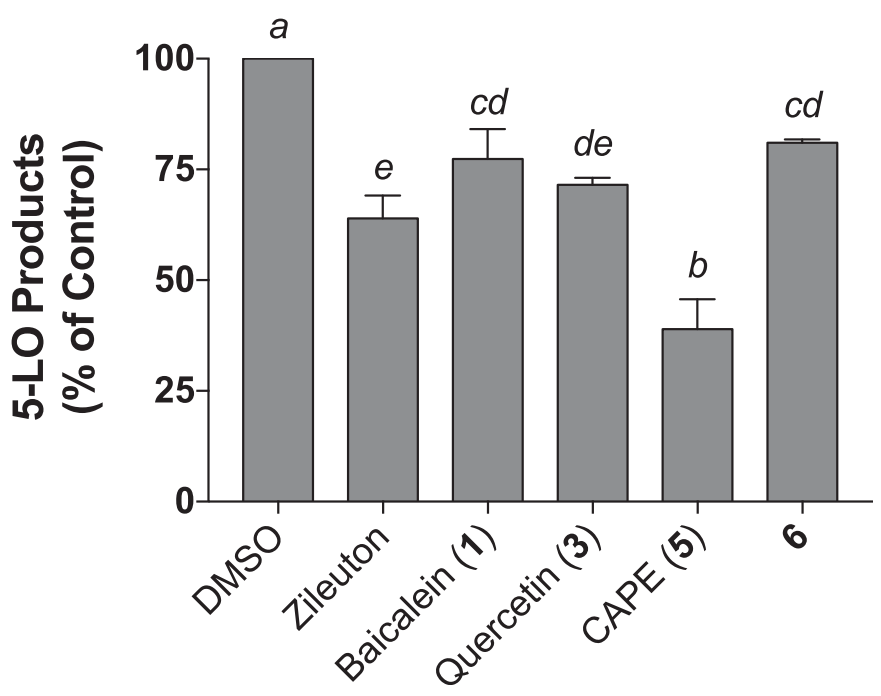

Fig. 7. Inhibitory effect of the compounds on 5 -LO product biosynthesis in HEK293 cells. Stably transfected HEK293 cells expressing both 5-LO and 5 -LO activating protein were preincubated with the indicated inhibitors for 5 minutes at $37^{\circ} \mathrm{C}$ prior to stimulation with $10 \mu \mathrm{M}$ calcium ionophore $\mathrm{A} 23187$ and $40 \mu \mathrm{M}$ arachidonic acid for another 15 minutes at $37^{\circ} \mathrm{C}$. RP-HPLC quantification of 5-LO products [leukotriene $\mathrm{B}_{4}\left(\mathrm{LTB}_{4}\right), 6$-trans $\mathrm{LTB}_{4}$, 6-trans-12-epi $\mathrm{LTB}_{4}$, and 5-HETE] was performed as previously described (Boudreau et al., 2011; Allain et al., 2015). Results are expressed as the mean \pm S.D. of three independent experiments. Values that do not have a common superscript are statistically different $(P<0.05)$ as determined by one-way analysis of variance followed by Tukey's multiple comparisons test.

when compared with the reference molecules baicalein (compound 1) and CAPE (compound 5). In the second part of the study, we evaluated the selectivity of the compounds by assessing their ability to interfere with the 5-LO and COX-1 pathways, also implicated in the generation of eicosanoids. Finally, we evaluated potential off-targeted effects that could be attributed to our compounds, such as mitochondrial respiration and platelet activation.

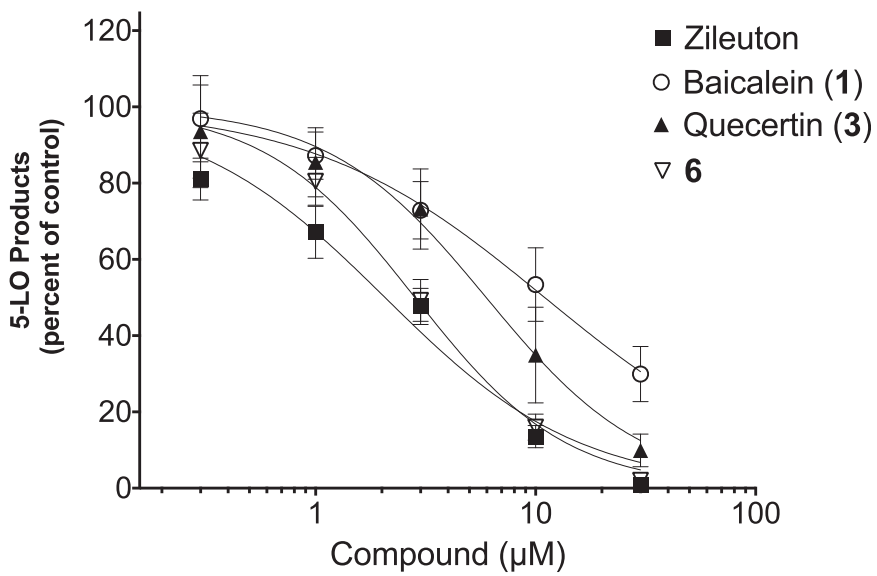

Fig. 8. Impact of selected compounds on 5-LO product synthesis by isolated human PMNLs. Prewarmed human PMNLs isolated from peripheral blood were preincubated with the specific compounds at the indicated concentrations for 5 minutes at $37^{\circ} \mathrm{C}$. Then, 5 -LO product biosynthesis was initiated by stimulating PMNLs for 15 minutes with $1 \mu \mathrm{M}$ thapsigargin and $10 \mu \mathrm{M}$ arachidonic acid. 5-LO products [leukotriene $\mathrm{B}_{4}\left(\mathrm{LTB}_{4}\right)$, 6-trans $\mathrm{LTB}_{4}$, 6-trans-12-epi $\mathrm{LTB}_{4}, 20$-hydroxy-LTB 4 , 20-carboxy- $\mathrm{LTB}_{4}$, and 5-HETE] were quantified using RP-HPLC as previously described (Boudreau et al., 2011; Allain et al., 2015). Results are expressed as the mean \pm S.D. of four independent experiments each performed in duplicate.
TABLE 6

Calculated $\mathrm{IC}_{50}$ values of selected compounds for the inhibition of 5-LO product biosynthesis in human PMNLs

Values are the mean $\pm 95 \%$ confidence interval from four independent experiments.

\begin{tabular}{lc}
\hline \multicolumn{1}{c}{ Compound } & $\mathrm{IC}_{50}(95 \% \mathrm{CI})$ \\
\hline Zileuton & $\mu M$ \\
Baicalein (compound 1) & $2.07(1.71-2.51)$ \\
Quercetin (compound 3) & $11(8.44-14.33)$ \\
Compound $\mathbf{6}$ & $5.97(4.64-7.67)$ \\
\hline
\end{tabular}

CI, confidence interval.

Starting with quercetin (compound 3), the most well-known hydroxyflavone and the one that demonstrated the most antiinflammatory activity, we performed acetylation and methylation of all phenolic hydroxyls to investigate the effect of better bioavailability/stability (Fig. 2). Bioavailability- and stabilityimproving ester prodrugs have already been developed for many drugs with phenolic hydroxyls (Boudreau et al., 2012, 2017; Allain et al., 2015), as has been demonstrated for compound 6 (Israel et al., 1993; Sud'ina et al., 1993; Boudreau et al., 2012). However, the effects of acetylation and methylation on our selected enzymes had not been previously investigated. Therefore, the goal of this study was to evaluate and characterize newly synthetized compounds as novel 12-LO inhibitors with superior selectivity than the current reference molecules used by researchers in the field.

First, we evaluated the capacity of our compounds to inhibit the 12-LO pathway in freshly isolated human platelets. Exogenous arachidonic acid was added to eliminate the constraint that our compounds could interfere with its release from the cell's membrane via phospholipase $\mathrm{A}_{2}$, thus preventing a critical step in the bioavailability of the 12-LO substrate (Rossi et al., 2010; Boudreau et al., 2012; Meirer et al., 2014). Using baicalein (compound 1) and CAPE (compound 5) in our experimental approach as reference inhibitors of the 12-LO pathway (Deschamps et al., 2006; Boudreau et al., 2017), we found that quercetin (compound $\mathbf{3}$ ) and compound $\mathbf{6}$ were the only compounds capable of inhibiting the $12-\mathrm{LO}$ pathway in human platelets with potency similar to that of the reference

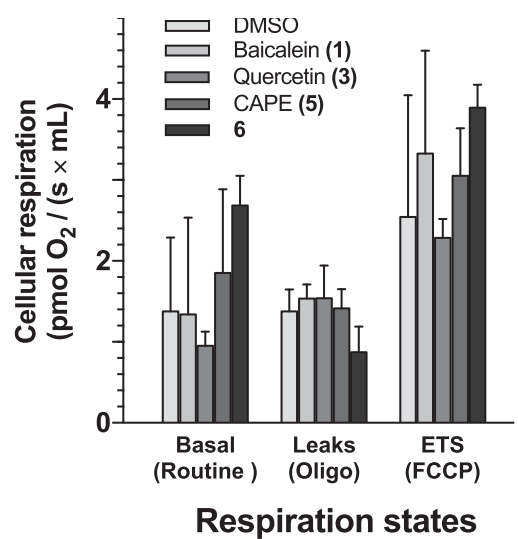

Fig. 9. Respiration states and ratio of platelets coincubated with DMSO (control) or the indicated compounds. No significant differences were detected between treatments with compounds, as determined by one-way analysis of variance followed by Tukey's multiple comparison tests. Values are the mean \pm S.D. of at least three independent experiments each performed in duplicate. 


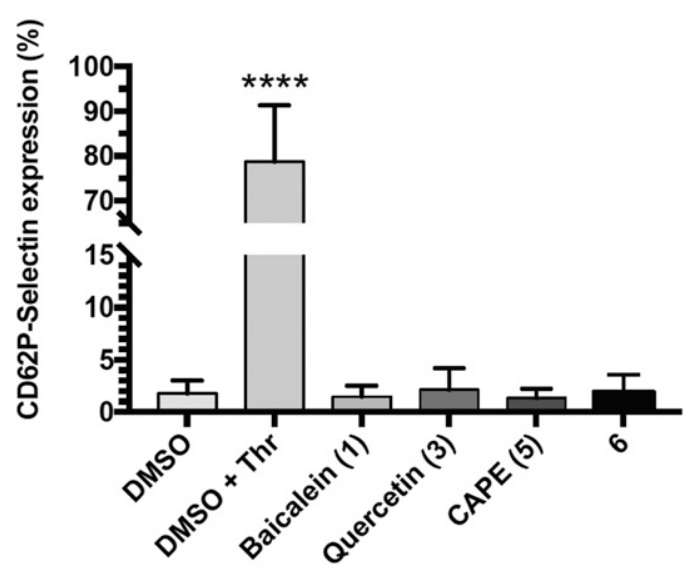

Fig. 10. Percentages of CD62P-selectin expression following flow cytometry analysis on freshly isolated platelets following coincubation with the tested compounds. Platelets in the presence of DMSO and thrombine (as a positive control for platelet activation) were significantly different compared with other compounds as determined by one-way analysis of variance followed by Tukey's multiple comparison tests. Values are the mean \pm S.D. from four independent experiments $(* * * * P<0.001)$.

molecules at the tested concentration of $1 \mu \mathrm{M}$. However, none of the compounds tested, including our reference molecules baicalein (compound 1) and CAPE (compound 5) were significantly better inhibitors of the 12-LO pathway when we performed dose-response experiments. While this may suggest that none of our tested compounds are better in vitro than the reference molecules, other characterization parameters should be considered, such as inflammation pathway selectivity and offtarget effects affecting normal cell functions, before coming to a conclusion regarding the potential of these compounds.

Having established that quercetin (compound 3) and compound 6 were the only compounds capable of inhibiting the 12-LO pathway in vitro, we decided to pursue further characterization of their mechanism of action and their potential interference with the enzyme. In addition to the 12-LO enzyme, which converts arachidonic acid into 12(S)-HETE, platelets also constitutively express COX-1, which is the pathway responsible for the conversion of arachidonic acid into thromboxane $\mathrm{A}_{2}$ and 12-HHT (Narumiya, 2003). Using 12-HHT, which is generated in equimolar quantities with thromboxane $\mathrm{A}_{2}$, we found that fully acetylated compound $\mathbf{6}$ slightly inhibited the COX-1 pathway in human platelets. In contrast, baicalein (compound 1), quercetin (compound 3), and CAPE (compound 5) all exhibited some level of inhibition of 12-HHT biosynthesis. These results suggest that compound $\mathbf{6}$ demonstrates a selectivity for the 12-LO enzyme in human platelets. Therefore, normal platelet functions such as aggregation and adherence, which are critical for the reduction of blood loss due to vascular injuries, should not be affected by compound $\mathbf{6}$.

In addition, we investigated the compounds' abilities to inhibit another lipoxygenase pathway, that of 5-LO. The 5-LO enzyme is responsible for the conversion of arachidonic acid into leukotrienes, which are potent bioactive molecules necessary for host defense but also play an important role in chronic inflammation (Peters-Golden and Henderson, 2007). The 5-LO enzyme is primarily expressed in myeloid cells, including granulocytes, B cells, and mast cells, while platelets do not express the enzyme. Since leukotrienes are key mediators in inflammatory diseases, it is not surprising that the 5-LO pathway has been the subject of numerous therapeutic approaches in recent years (Pergola and Werz, 2010; Hofmann and Steinhilber, 2013). In contrast to 12-LO, 5-LO has been the subject of several therapeutic approaches for years (Hofmann and Steinhilber, 2013; Steinhilber and Hofmann, 2014), which resulted in the development of zileuton (Zyflo), the only clinically approved 5-LO inhibitor (Israel et al., 1993; Nelson et al., 2007). Most flavonoids that display inhibitory properties for the 5-LO enzyme also exhibit some degree of 12-LO inhibition (Altavilla et al., 2012; Ribeiro et al., 2014). However, the development of new inhibitors that exhibit selectivity for one or the other enzymes, allowing the inhibition of one inflammatory pathway at a time, has been the focus of some research (Pergola and Werz, 2010; Hofmann and Steinhilber, 2013). To evaluate the affinity of our compounds for the 5-LO pathway, we used HEK293 cells stably transfected with the necessary machinery to convert arachidonic acid into leukotrienes (Boudreau et al., 2012, 2017; Allain et al., 2015). While compound 6 slightly inhibited the production of leukotrienes, its potency was significantly lower than that of CAPE (compound 5) and zileuton, both wellknown direct inhibitors of the 5-LO enzyme (Israel et al., 1993; Sud'ina et al., 1993; Boudreau et al., 2012). When investigating potential inhibitors of the 5-LO pathway, we usually aim for compounds that have similar or better potency than CAPE (compound 5) (Boudreau et al., 2012, 2017) in regard to their ability to decrease leukotriene production (Boudreau et al., 2012, 2017). However, in human PMNL assays, compound 6 inhibited 5-LO product biosynthesis in the same line as zileuton. While compound 6 remains a more selective inhibitor of the 12-LO pathway in platelets, it would be worth exploring its role as a potential dual lipoxygenase inhibitor in future studies.

In the next series of experiments, we evaluated several mechanisms by which compound 6 could prevent the biosynthesis of platelet-derived $12(\mathrm{~S})$-HETE. While baicalein (compound 1) and quercetin (compound 3) demonstrated potent free radical scavenger activity in the same range as the well-known antioxidant ascorbic acid, the fully acetylated compound 6 was unable to scavenge the free radical DPPH. These results demonstrate that compound $\mathbf{6}$ does not interfere with $12(S)$-HETE by preventing the oxygenation of the 12 th carbon on arachidonic acid, and we therefore investigated another potential interfering mechanism.

Using molecular docking with soybean 15-LO (PDB: 1N8Q), CAPE (compound 5) exhibits properties that make it a great candidate for inhibition of the lipoxygenase family. Indeed, it had consistently good affinity scores, and makes consistent interactions with different oxygenase proteins. From this analysis, it was found that His518 and Phe576 may help the tested molecules position and stabilize themselves near the catalytic iron. More specifically, His518 is one of the residues coordinating the iron atom. This means that an interaction with this residue will certainly be helpful in bringing the ligand closer and possibly within the range for interaction with the iron atom.

Of the tested molecules, baicalein (compound 1) made the most important interactions. It interacted directly with the iron atom (Fig. 11), and with conveniently placed $\pi-\pi$ interactions baicalein (compound 1) appeared to be a wellsuited candidate for the inhibition of 12-LO. The other three molecules, while not directly interacting with the iron atom, placed themselves within reach of interaction. 


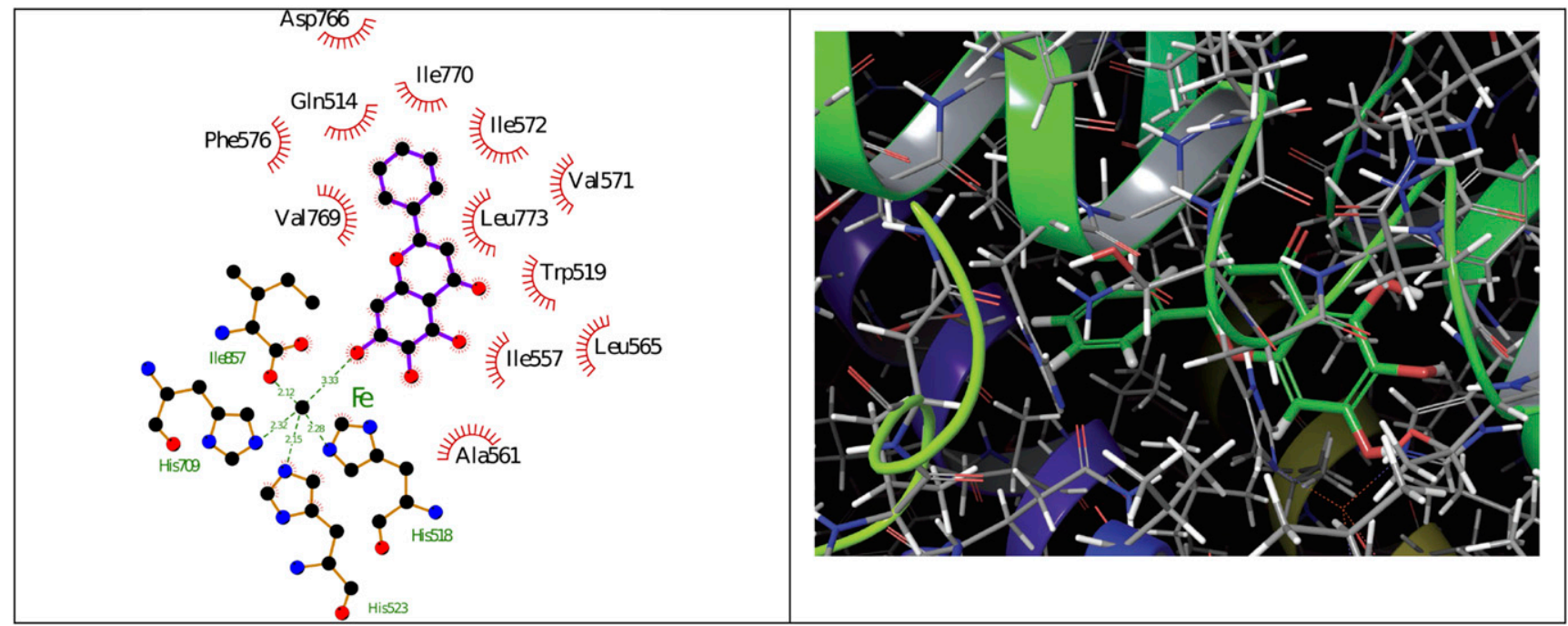

Fig. 11. Two-dimensional (Ligplot+) and three-dimensional (Maestro) images of baicalein (compound 1).

Due to compound 6's larger size, it seems to be favored by larger and more open active site cavities. Compound $\mathbf{6}$ may be too large to fit inside the smaller cavities or it may generate too many bad interactions inside the smaller cavities such as in 1N8Q. Care should be taken with the results of compound 6 in 3D3L since the crystal structure is missing residues. A complete crystal structure of the human 12-LO may reduce the size of the active site cavity; thus compound 6's affinity would also potentially decrease.

Finally, we investigated potential off-target effects of our compounds. Since platelets are anucleate cells, typical propidium iodide and annexin-V labeling cannot be performed to evaluate the cell's viability. Therefore, we investigated the modulatory effects of our compounds on the platelet's mitochondrial respiration by a high-resolution respirometry assay as previously reported (Boudreau et al., 2014; Bynum et al., 2016). All of the compounds tested, including compound $\mathbf{6}$, did not significantly modulate the mitochondrial oxygen consumption of the platelets when compared with the vehicle (DMSO), nor did it affect the ETS coupling efficiency.

Eicosanoids are important mediators of the inflammatory response. While this response is necessary for the host defense

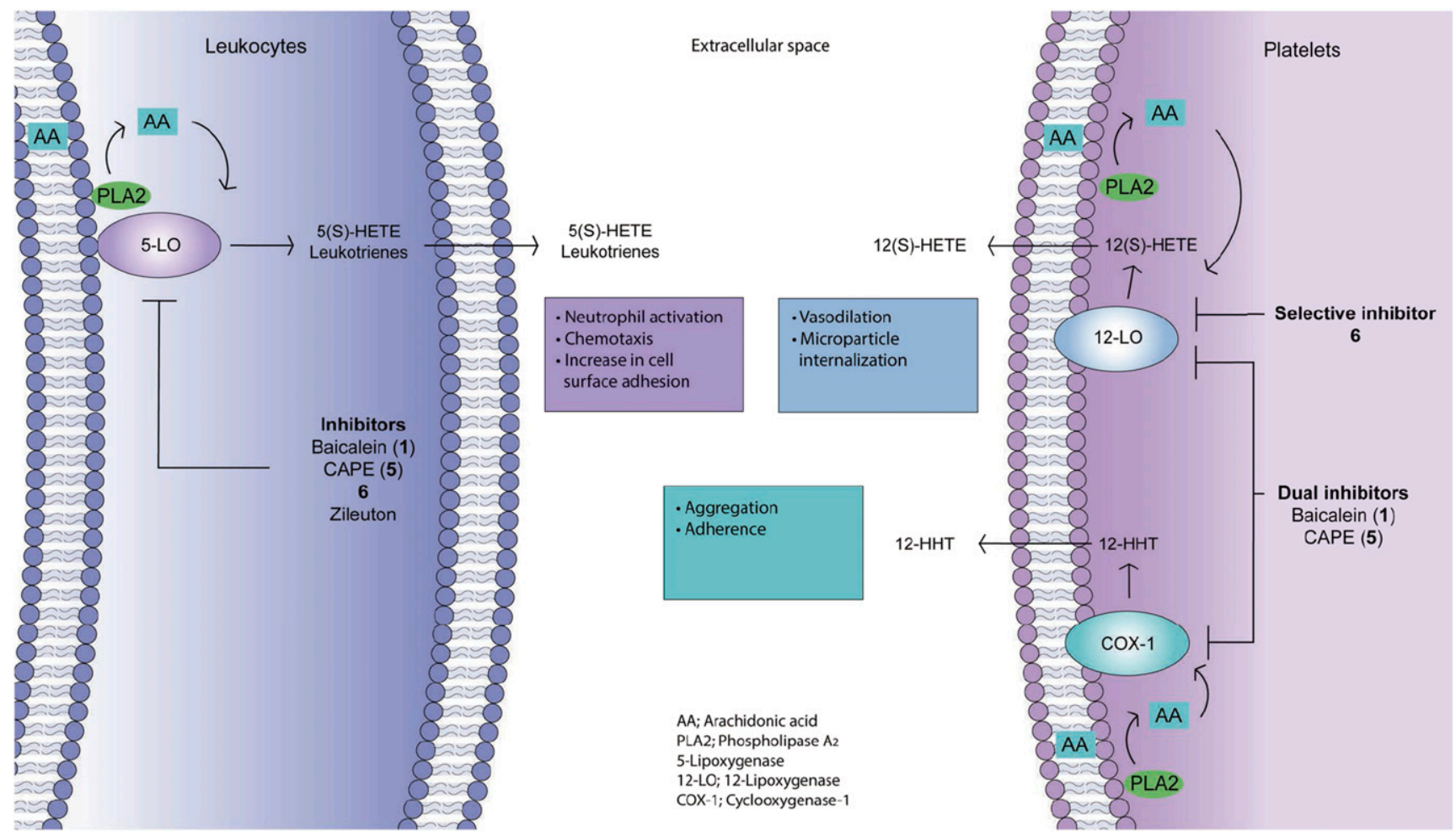

Fig. 12. Enzyme inhibition of the compounds tested in this study. 
against pathogens, eicosanoids have been associated with several types of chronic inflammatory diseases. Hence, enzymes implicated in the production of eicosanoids have been strategically targeted for potential therapeutic approaches for years. Our results strongly suggest that compound 6 might be a better alternative to baicalein as a 12 -LO inhibitor reference molecule. In addition, we provide insight into the fundamental mechanism by which compound 6 acts as an inhibitor of the 12-LO pathway (Fig. 12), a neglected enzyme in inflammatory diseases. While several characterizations of the compound's ability to inhibit the production of $12(\mathrm{~S})$-HETE have been performed in this study, future pharmacokinetics investigations should provide critical information on the compound's potential as a novel therapeutic drug for inflammatory diseases. The development of new and potent 12-LO inhibitory compounds may serve as novel therapeutic approaches in several inflammatory diseases in which $12(\mathrm{~S})$-HETE is abundantly present (Porro et al., 2014; Duchez et al., 2015; Ehses and Donath, 2015; Hong et al., 2015).

\section{Authorship Contributions}

Participated in research design: Doucet, Surette, Pichaud, Touaibia, Boudreau.

Conducted experiments and preformed data analysis: Doucet, Jougleux, Poirier, Cormier, Léger.

Wrote or contributed to the writing of the manuscript: Doucet, Surette, Touaibia, Boudreau.

\section{References}

Allain EP, Boudreau LH, Flamand N, and Surette ME (2015) The intracellular localisation and phosphorylation profile of the human 5 -lipoxygenase $\Delta 13$ isoform differs from that of its full length counterpart. PLoS One 10:e0132607.

Altavilla D, Minutoli L, Polito F, Irrera N, Arena S, Magno C, Rinaldi M, Burnett BP, Squadrito F, and Bitto A (2012) Effects of flavocoxid, a dual inhibitor of COX and 5 -lipoxygenase enzymes, on benign prostatic hyperplasia. $\mathrm{Br} J$ Pharmacol 167: 95-108.

Boilard E, Larabee K, Shnayder R, Jacobs K, Farndale RW, Ware J, and Lee DM (2011) Platelets participate in synovitis via Cox-1-dependent synthesis of prostacyclin independently of microparticle generation. J Immunol 186:4361-4366.

Boudreau LH, Bertin J, Robichaud PP, Laflamme M, Ouellette RJ, Flamand N, and Surette ME (2011) Novel 5-lipoxygenase isoforms affect the biosynthesis of 5-lipoxygenase products. FASEB J 25:1097-1105.

Boudreau LH, Duchez AC, Cloutier N, Soulet D, Martin N, Bollinger J, Paré A, Rousseau M, Naika GS, Lévesque T, et al. (2014) Platelets release mitochondria serving as substrate for bactericidal group IIA-secreted phospholipase A2 to promote inflammation. Blood 124:2173-2183.

Boudreau LH, Lassalle-Claux G, Cormier M, Blanchard S, Doucet MS, Surette ME, and Touaibia M (2017) New hydroxycinnamic acid esters as novel 5-lipoxygenase inhibitors that affect leukotriene biosynthesis. Mediators Inflamm 2017:6904634.

Boudreau LH, Maillet J, LeBlanc LM, Jean-François J, Touaibia M, Flamand N, and Surette ME (2012) Caffeic acid phenethyl ester and its amide analogue are potent inhibitors of leukotriene biosynthesis in human polymorphonuclear leukocytes. PLoS One 7:e31833-e31838.

Bynum JA, Meledeo MA, Getz TM, Rodriguez AC, Aden JK, Cap AP, and Pidcoke HF (2016) Bioenergetic profiling of platelet mitochondria during storage: $4^{\circ} \mathrm{C}$ storage extends platelet mitochondrial function and viability. Transfusion 56 (Suppl 1): S76-S84.

Cárdenas M, Marder M, Blank VC, and Roguin LP (2006) Antitumor activity of some natural flavonoids and synthetic derivatives on various human and murine cancer cell lines. Bioorg Med Chem 14:2966-2971.

Chen M, Boilard E, Nigrovic PA, Clark P, Xu D, Fitzgerald GA, Audoly LP, and Lee DM (2008) Predominance of cyclooxygenase 1 over cyclooxygenase 2 in the generation of proinflammatory prostaglandins in autoantibody-driven $\mathrm{K} / \mathrm{BxN}$ serumtransfer arthritis. Arthritis Rheum 58:1354-1365.

Chen M, Lam BK, Kanaoka Y, Nigrovic PA, Audoly LP, Austen KF, and Lee DM (2006) Neutrophil-derived leukotriene B4 is required for inflammatory arthritis. J Exp Med 203:837-842.

Chouinard F, Turcotte C, Guan X, Larose MC, Poirier S, Bouchard L, Provost V, Flamand L, Grandvaux N, and Flamand N (2013) 2-Arachidonoyl-glycerol- and arachidonic acid-stimulated neutrophils release antimicrobial effectors against E. coli, S. aureus, HSV-1, and RSV. J Leukoc Biol 93:267-276.

Cormier M, Ghouili F, Roumaud P, Martin LJ, and Touaibia M (2017) Influence of flavonols and quercetin derivative compounds on MA-10 Leydig cells steroidogenic genes expressions. Toxicol In Vitro 44:111-121.

Cyrus T, Witztum JL, Rader DJ, Tangirala R, Fazio S, Linton MF, and Funk CD (1999) Disruption of the 12/15-lipoxygenase gene diminishes atherosclerosis in apo E-deficient mice. $J$ Clin Invest 103:1597-1604.

De Clercq E and Field HJ (2006) Antiviral prodrugs-the development of successful prodrug strategies for antiviral chemotherapy. Br J Pharmacol 147:1-11.
Deschamps JD, Kenyon VA, and Holman TR (2006) Baicalein is a potent in vitro inhibitor against both reticulocyte 15-human and platelet 12-human lipoxygenases. Bioorg Med Chem 14:4295-4301.

Ding XZ, Tong WG, and Adrian TE (2001) 12-lipoxygenase metabolite 12(S)-HETE stimulates human pancreatic cancer cell proliferation via protein tyrosine phosphorylation and ERK activation. Int $J$ Cancer 94:630-636.

Doiron JA, Métayer B, Richard RR, Desjardins D, Boudreau LH, Levesque NA, JeanFrançois J, Poirier SJ, Surette ME, and Touaibia M (2014) Clicked cinnamic/caffeic esters and amides as radical scavengers and 5-lipoxygenase inhibitors. Int $\mathrm{J} \mathrm{Med}$ Chem 2014:931756.

Duchez AC, Boudreau LH, Naika GS, Bollinger J, Belleannée C, Cloutier N, Laffont B, Mendoza-Villarroel RE, Lévesque T, Rollet-Labelle E, et al. (2015) Platelet microparticles are internalized in neutrophils via the concerted activity of 12-lipoxygenase and secreted phospholipase A2-IIA [published correction appears in Proc Natl Acad Sci USA (2015) 112:E6825]. Proc Natl Acad Sci USA 112 E3564-E3573.

Ehses JA and Donath MY (2015) Targeting 12-lipoxygenase as a novel strategy to combat the effects of inflammation on beta cells in diabetes. Diabetologia 58: $425-428$.

Faraci FM, Sobey CG, Chrissobolis S, Lund DD, Heistad DD, and Weintraub NL (2001) Arachidonate dilates basilar artery by lipoxygenase-dependent mechanism and activation of $\mathrm{K}^{+}$channels. Am $J$ Physiol Regul Integr Comp Physiol 281: R246-R253.

Ferrándiz ML and Alcaraz MJ (1991) Anti-inflammatory activity and inhibition of arachidonic acid metabolism by flavonoids. Agents Actions 32:283-288.

Funk CD, Furci L, and FitzGerald GA (1990) Molecular cloning, primary structure, and expression of the human platelet/erythroleukemia cell 12-lipoxygenase. Proc Natl Acad Sci USA 87:5638-5642.

Gerstmeier J, Weinigel C, Barz D, Werz O, and Garscha U (2014) An experimental cell-based model for studying the cell biology and molecular pharmacology of 5-lipoxygenase-activating protein in leukotriene biosynthesis. Biochim Biophys Acta 1840:2961-2969.

Giera M, Ioan-Facsinay A, Toes R, Gao F, Dalli J, Deelder AM, Serhan CN, and Mayboroda OA (2012) Lipid and lipid mediator profiling of human synovial fluid in rheumatoid arthritis patients by means of LC-MS/MS. Biochim Biophys Acta 1821:1415-1424.

Gnaiger E (2012) Mitochondrial pathways and respiratory control, in An Introduction to OXPHOS analysis, 3rd ed, pp 88, Mitochondr Physiol Network 19.12. Oroboros MiPNet Publications, Innsbruck.

Gnaiger E and Kuznetsov AV (2002) Mitochondrial respiration at low levels of oxygen and cytochrome $c$. Biochem Soc Trans 30:252-258.

Hamberg M and Samuelsson B (1974) Prostaglandin endoperoxides. Novel transformations of arachidonic acid in human platelets. Proc Natl Acad Sci USA 71: $3400-3404$

Hofmann B and Steinhilber D (2013) 5-Lipoxygenase inhibitors: a review of recent patents (2010-2012). Expert Opin Ther Pat 23:895-909.

Hong SH, Han JE, Ko JS, Do SH, Lee EH, and Cho MH (2015) Quantitative determination of 12-hydroxyeicosatetraenoic acids by chiral liquid chromatography tandem mass spectrometry in a murine atopic dermatitis model. $J$ Vet Sci 16: $307-315$

Honn KV, Tang DG, Gao X, Butovich IA, Liu B, Timar J, and Hagmann W (1994) 12 lipoxygenases and 12(S)-HETE: role in cancer metastasis. Cancer Metastasis Rev 13:365-396.

Israel E, Rubin P, Kemp JP, Grossman J, Pierson W, Siegel SC, Tinkelman D, Murray JJ, Busse W, Segal AT, et al. (1993) The effect of inhibition of 5-lipoxygenase by zileuton in mild-to-moderate asthma. Ann Intern Med 119: 1059-1066.

Kang KH, Ling TY, Liou HH, Huang YK, Hour MJ, Liou HC, and Fu WM (2013) Enhancement role of host 12/15-lipoxygenase in melanoma progression. Eur $J$ Cancer 49:2747-2759.

Krump E, Picard S, Mancini J, and Borgeat P (1997) Suppression of leukotriene B biosynthesis by endogenous adenosine in ligand-activated human neutrophils. $J$ Exp Med 186:1401-1406.

Lapchak PA, Maher P, Schubert D, and Zivin JA (2007) Baicalein, an antioxidant 12/15-lipoxygenase inhibitor improves clinical rating scores following multiple infarct embolic strokes. Neuroscience 150:585-591.

Laskowski RA and Swindells MB (2011) LigPlot+: multiple ligand-protein interaction diagrams for drug discovery. J Chem Inf Model 51:2778-2786.

Leff JA, Busse WW, Pearlman D, Bronsky EA, Kemp J, Hendeles L, Dockhorn R, Kundu S, Zhang J, Seidenberg BC, et al. (1998) Montelukast, a leukotrienereceptor antagonist, for the treatment of mild asthma and exercise-induced bronchoconstriction. N Engl J Med 339:147-152

Liu B, Maher RJ, De Jonckheere JP, Popat RU, Stojakovic S, Hannun YA, Porter AT, and Honn KV (1997) 12(S)-HETE increases the motility of prostate tumor cells through selective activation of PKC alpha. Adv Exp Med Biol 400B:707-718.

Liu MC, Dubé LM, and Lancaster J; Zileuton Study Group (1996) Acute and chronic effects of a 5-lipoxygenase inhibitor in asthma: a 6-month randomized multicenter trial. J Allergy Clin Immunol 98:859-871.

Macready AL, George TW, Chong MF, Alimbetov DS, Jin Y, Vidal A, Spencer JP Kennedy OB, Tuohy KM, Minihane AM, et al.; FLAVURS Study Group (2014) Flavonoid-rich fruit and vegetables improve microvascular reactivity and inflammatory status in men at risk of cardiovascular disease-FLAVURS: a randomized controlled trial. Am J Clin Nutr 99:479-489.

Mehrabian M, Allayee H, Wong J, Shi W, Wang XP, Shaposhnik Z, Funk CD, and Lusis AJ (2002) Identification of 5-lipoxygenase as a major gene contributing to atherosclerosis susceptibility in mice [published correction appears in Circ Res (2002) 91:e27]. Circ Res 91:120-126.

Meirer K, Steinhilber D, and Proschak E (2014) Inhibitors of the arachidonic acid cascade: interfering with multiple pathways. Basic Clin Pharmacol Toxicol 114: 83-91. 
Moalin M, Strijdonck GPFV, Beckers M, Hagemen G, Borm P, Bast A, and Haenen GRMM (2011) A planar conformation and the hydroxyl groups in the B and C rings play a pivotal role in the antioxidant capacity of quercetin and quercetin derivatives. Molecules 16:9636-9650.

Murakami T, Komiyama Y, Masuda M, Kido H, Nomura S, Fukuhara S, Karakawa M, Iwasaka T, and Takahashi $\mathrm{H}$ (1996) Flow cytometric analysis of platelet activation markers CD62P and CD63 in patients with coronary artery disease. Eur $J$ Clin Invest 26:996-1003.

Narumiya S (2003) Prostanoids in immunity: roles revealed by mice deficient in their receptors. Life Sci 74:391-395.

Nelson H, Kemp J, Berger W, Corren J, Casale T, Dube L, Walton-Bowen K, LaVallee N, and Stepanians M (2007) Efficacy of zileuton controlled-release tablets administered twice daily in the treatment of moderate persistent asthma: a 3-month randomized controlled study. Ann Allergy Asthma Immunol 99:178-184.

Nguyen CH, Stadler S, Brenner S, Huttary N, Krieger S, Jäger W, Dolznig H, and Krupitza G (2016) Cancer cell-derived 12(S)-HETE signals via 12-HETE receptor, RHO, ROCK and MLC2 to induce lymph endothelial barrier breaching. $\mathrm{Br} J$ Cancer 115:364-370.

Nuñez C, Morales N, García-Beltran O, Mascayano C, and Fierro A (2017) Discovery two potent and new inhibitors of 15-lipoxygenase: $(E)$-3-((3,4-dihydroxybenzylidene) amino)-7-hydroxy-2H-chromen-2-one and $(E)$-O-(4-(( 7-hydroxy-2-oxo-2H-chromen-3yl) imino)methine) phenyl)dimethylcarbamothioate. Med Chem Res 26:2707-2717.

Okuno T, Iizuka Y, Okazaki H, Yokomizo T, Taguchi R, and Shimizu T (2008) 12(S)Hydroxyheptadeca-5Z, 8E, 10E-trienoic acid is a natural ligand for leukotriene B4 receptor 2. J Exp Med 205:759-766.

Pérez-Cano FJ and Castell M (2016) Flavonoids, inflammation and immune system. Nutrients 8:659.

Pergola C and Werz O (2010) 5-Lipoxygenase inhibitors: a review of recent developments and patents. Expert Opin Ther Pat 20:355-375.

Pesta D and Gnaiger E (2012) High-resolution respirometry: OXPHOS protocols for human cells and permeabilized fibers from small biopsies of human muscle. Methods Mol Biol 810:25-58.

Peters-Golden M and Henderson WR Jr (2007) Leukotrienes. N Engl J Med 357: 1841-1854.

Picq M, Prigent AF, Némoz G, André AC, and Pacheco H (1982) Pentasubstituted quercetin analogues as selective inhibitors of particulate $3^{\prime}: 5^{\prime}$-cyclic-AMP phosphodiesterase from rat brain. J Med Chem 25:1192-1198.

Porro B, Songia P, Squellerio I, Tremoli E, and Cavalca V (2014) Analysis, physiological and clinical significance of 12-HETE: a neglected platelet-derived 12-lipoxygenase product. J Chromatogr B Analyt Technol Biomed Life Sci 964 $26-40$

Ribeiro D, Freitas M, Tomé SM, Silva AMS, Laufer S, Lima JLFC, and Fernandes E (2015) Flavonoids inhibit COX-1 and COX-2 enzymes and cytokine/chemokine production in human whole blood. Inflammation 38:858-870.

Ribeiro D, Freitas M, Tomé SM, Silva AMS, Porto G, Cabrita EJ, Marques MMB, and Fernandes E (2014) Inhibition of LOX by flavonoids: a structure-activity relationship study. Eur J Med Chem 72:137-145.
Robichaud PP, Poirier SJ, Boudreau LH, Doiron JA, Barnett DA, Boilard E, and Surette ME (2016) On the cellular metabolism of the click chemistry probe 19-alkyne arachidonic acid. J Lipid Res 57:1821-1830.

Rossi A, Pergola C, Koeberle A, Hoffmann M, Dehm F, Bramanti P, Cuzzocrea S, Werz O, and Sautebin L (2010) The 5-lipoxygenase inhibitor, zileuton, suppresses prostaglandin biosynthesis by inhibition of arachidonic acid release in macrophages. Br J Pharmacol 161:555-570.

Sarveswaran S, Chakraborty D, Chitale D, Sears R, and Ghosh J (2015) Inhibition of 5 -lipoxygenase selectively triggers disruption of c-Myc signaling in prostate cancer cells. J Biol Chem 290:4994-5006.

Sekiya K and Okuda H (1982) Selective inhibition of platelet lipoxygenase by baicalein. Biochem Biophys Res Commun 105:1090-1095.

Steinhilber D and Hofmann B (2014) Recent advances in the search for novel 5lipoxygenase inhibitors. Basic Clin Pharmacol Toxicol 114:70-77.

Sud'ina GF, Mirzoeva OK, Pushkareva MA, Korshunova GA, Sumbatyan NV, and Varfolomeev SD (1993) Caffeic acid phenethyl ester as a lipoxygenase inhibitor with antioxidant properties. FEBS Lett 329:21-24.

Surette ME, Winkler JD, Fonteh AN, and Chilton FH (1996) Relationship between arachidonate-phospholipid remodeling and apoptosis. Biochemistry 35:9187-9196.

Tardif JC, L'allier PL, Ibrahim R, Grégoire JC, Nozza A, Cossette M, Kouz S, Lavoie MA, Paquin J, Brotz TM, et al. (2010) Treatment with 5-lipoxygenase inhibitor VIA-2291 (Atreleuton) in patients with recent acute coronary syndrome. Circ Cardiovasc Imaging 3:298-307.

Tolba MF, Azab SS, Khalifa AE, Abdel-Rahman SZ, and Abdel-Naim AB (2013) Caffeic acid phenethyl ester, a promising component of propolis with a plethora of biological activities: a review on its anti-inflammatory, neuroprotective, hepatoprotective, and cardioprotective effects. IUBMB Life 65:699-709.

Trott O and Olson AJ (2010) AutoDock Vina: improving the speed and accuracy of docking with a new scoring function, efficient optimization, and multithreading. $J$ Comput Chem 31:455-461.

Wecksler AT, Garcia NK, and Holman TR (2009) Substrate specificity effects of lipoxygenase products and inhibitors on soybean lipoxygenase-1. Bioorg Med Chem 17:6534-6539.

Werz O (2007) Inhibition of 5-lipoxygenase product synthesis by natural compounds of plant origin. Planta Med 73:1331-1357.

Xu J, Zhang Y, Xiao Y, Ma S, Liu Q, Dang S, Jin M, Shi Y, Wan B, and Zhang Y (2013) Inhibition of $12 / 15$-lipoxygenase by baicalein induces microglia $\mathrm{PPAR} \beta / \delta$ : a potential therapeutic role for CNS autoimmune disease. Cell Death Dis 4:e569.

Address correspondence to: Mohamed Touaibia, Department of Chemistry and Biochemistry, Université de Moncton, 18 Ave Antonine Maillet, RémiRossignol, Moncton, Canada E1A 3E9. E-mail: mohamed.touaibia@umoncton.ca; or Luc H. Boudreau, Department of Chemistry and Biochemistry, Université de Moncton, 18 Ave Antonine Maillet, Rémi-Rossignol, Moncton, Canada E1A 3E9. E-mail: luc.boudreau@umoncton.ca 